University of Windsor

Scholarship at UWindsor

\title{
Argument from Expert Opinion as Legal Evidence: Critical Questions and Admissibility Criteria of Expert Testimony in the American Legal System
}

David M. Godden

Douglas Walton

University of Windsor

Follow this and additional works at: https://scholar.uwindsor.ca/crrarpub

Part of the Courts Commons

\section{Recommended Citation}

Godden, David M. and Walton, Douglas. (2006). Argument from Expert Opinion as Legal Evidence: Critical Questions and Admissibility Criteria of Expert Testimony in the American Legal System. Ratio Juris, 19 (3), 261-286.

https://scholar.uwindsor.ca/crrarpub/4

This Article is brought to you for free and open access by the Centre for Research in Reasoning, Argumentation and Rhetoric (CRRAR) at Scholarship at UWindsor. It has been accepted for inclusion in CRRAR Publications by an authorized administrator of Scholarship at UWindsor. For more information, please contact scholarship@uwindsor.ca. 


\section{Argument from Expert Opinion as Legal Evidence: Critical Questions and Admissibility Criteria of Expert Testimony in the American Legal System*}

\section{DAVID M. GODDEN AND DOUGLAS WALTON}

Abstract. While courts depend on expert opinions in reaching sound judgments, the role of the expert witness in legal proceedings is associated with a litany of problems. Perhaps most prevalent is the question of under what circumstances should testimony be admitted as expert opinion. We review the changing policies adopted by American courts in an attempt to ensure the reliability and usefulness of the scientific and technical information admitted as evidence. We argue that these admissibility criteria are best seen in a dialectical context as a set of critical questions of the kind commonly used in models of argumentation.

There are four independent streams of research on expert opinion as evidence that are now at a point of convergence. The first is the longstanding concern in law with standards for the use of expert testimony in providing evidence in trials, and the changing rules for admissibility of this kind of evidence. The second is the growing literature in argumentation theory on argument from expert opinion as an argumentation scheme, or defeasible form of argument (Walton and Reed 2003). The third is the flowering of recent work in artificial intelligence and law (Schum 1994; Prakken and Sartor 1996, 2003), using argumentation schemes to represent forms of reasoning in law that are modeled in artificial intelligence (Walton 2005; Bex et al. 2003). In recent work of this sort, argument from expert

* Research for this paper was made possible by separate research grants from the Social Science and Humanities Research Council of Canada held by each of the authors. The authors would like to thank the anonymous reviewers of Ratio Juris for their helpful comments. 
opinion is the scheme most commonly taken as the leading case for studying how to identify, analyze and evaluate forms of argument used in law (Gordon 2005). The fourth is the new evidence scholarship (Anderson, Schum and Twining 2005) that applies technical tools and heuristics, like Wigmore diagrams, to the reconstruction of chains of evidential reasoning in trials, like the infamous trial of Sacco and Vanzetti. All four streams work with the same structure of rational argument, in which one party in a discussion uses the opinion of an expert to rationally convince another party to accept some proposition that the second party doubts. It is now long past time to bring these four streams together, so that researchers in each group can be informed about the parallel and overlapping work of researchers in the other three groups. The function of this paper is to carry out the interdisciplinary project of informing each of the four groups about how the work of the other groups relates to their own research initiatives. A large part of the problem for many scholars interested in expert opinion evidence is that Anglo-American law has undergone rapid and important changes in recent years, reflected in the changing criteria employed in the Federal Rules of Evidence (FRE). Thus a large part of the paper consists in summarizing and making sense of these developments in light of the concerns and methods of the other three streams of research. The goal is to put the problems currently faced in a clear perspective so that future interdisciplinary research on expert opinion evidence, of a kind that is much needed, will be made possible, and so that research in each field will be assisted.

\section{Expert Opinion in Argumentation and Law}

Argument from expert opinion (also called appeal to expert opinion) is a form of argument long held to be a fallacy in logic. However, recent work on argumentation has shown that it represents a form of reasoning that can sometimes be fallacious but that is often necessary, and can be reasonable under the right conditions of use (Walton 1997). The most obvious instance is the use of expert testimony in law, a form of argumentation that is so powerful and common in trials that it has now come to dominate as a form of evidence in Anglo-American law. American law, in particular, has struggled with the problem of devising criteria for dealing with expert opinion evidence, and it is the treatment of expert opinion in the American legal system that will be the focus of this paper. ${ }^{1}$ Many of us have heard

\footnotetext{
1 As Damaska 1997 has shown, it is mainly American law that approached the problem of expert evidence by providing a kind of criteria-based approach to admissibility. Continental law has relied on court-appointed experts and has tended to defer to them, while English law has approached the problem in a more gradualist manner (Damaska 1997, 151; Redmayne 2001). Indeed, especially following the Wolf reforms, the manner in which British courts have
} 
about landmark cases like Daubert ${ }^{2}$ and Kumho Tire ${ }^{3}$, and such cases have been tangentially written about in argumentation theory. But those working in argumentation have not so far been well informed about the evolution of these legal criteria and their relationship to the work on the argumentation scheme for appeal to expert opinion. This is a great shame, for in our opinion expert evidence in law is an important subject in its own right, but is also one in which argumentation can play an important role. It is a subject that shows to students of argumentation why argument from expert opinion, although problematic, is by no means inherently fallacious.

The argumentation scheme and its accompanying set of critical questions has become the tool of choice in argumentation studies for evaluating such arguments. We show how this scheme relates to the criteria, like the Daubert criteria, that have evolved in law to deal with expert testimony in trials. The main purpose of our exposition is to summarize the leading developments in the treatment of expert opinion evidence in law, from an argumentation perspective, and to show how current research on appeal to expert opinion as a form of fallible argumentation can help throw light on some serious problems with it. The ultimate goal of analyzing and evaluating such evidence as a species of rational argumentation by established criteria that have proved their worth is a collaborative research project for the future for argumentation researchers and legal professionals.

\section{The Dilemma of Expert Knowledge in Law}

The specialization of knowledge through scientific and technical advancement presents a unique dilemma to the legal system. On the one hand, we surely do not want the rulings and decisions of the court not to be founded on-or worse, to be at odds with-the best available technical or scientific knowledge (Black et al. 1994, 719). ${ }^{4}$ Yet, on the other hand, attempts to incorporate the technical and scientific elements of our knowledge into the legal procedure are associated with a litany of problems.

handled scientific evidence in civil proceedings has moved away from the American approach. Similarly, as Burkhard Schafer observed to us, in continental legal systems, the combination of the principle of free evaluation of proof-freie Beweiswürdigung in German law-(see Art 261 StPo [Criminal Procedural Code] and Art 286 ZPO [Civil procedural code]) and the inquisitorial principle (in Germany, Art 155ff StPo) ensure that there are no equivalent formal rules that constrain the judge in the use of expert witness testimony and give him wide ranging discretion in interpreting, accepting, or rejecting such evidence. On the limited rules on expert evidence, see Art 72-93 stop-none of them however deal with the issues discussed in the cases analyzed here.

${ }^{2}$ Daubert v Merrell Dow Pharmaceuticals, Inc., 509 U.S. 579, 1993.

3 Kumho Tire Co. v Patrick Carmichael, 119 S. Ct. 1167, 1999.

${ }^{4}$ For example, Black et al. cite a 1946 case (Berry v Chaplin, 169 P.2d 442 [Cal. Dist. Ct. App. 1946]) in which "a California court found that Charlie Chaplin had fathered a child, even though the child's blood type made paternity impossible" (ibid.). 
Perhaps the most general of these is that judges and juries are often required to make judgments in cases where they lack specific knowledge pertaining to the facts at issue in a case. The problem here is not so much one of the unavailability of evidence (which could also occur), as one of the fact-finder not having knowledge regarding the significance or probative weight of evidence that is available. Being ill-equipped to determine these matters for themselves, judges and juries must often rely on the knowledge of others in reaching their decisions.

Indeed, with the increasing role of technology and other highly specialized fields of knowledge in our society, courts have become increasingly dependent on experts in those fields when deciding upon matters. Quite often, the courts are dependent on experts in their attempts to reach informed, scientifically sound verdicts. For example, Owen (2002) observes that knowledge of product design and manufacture is often required when determining a liability issue relating to possible product defectiveness. "IJ]uries normally need the guidance of expert testimony to understand the technical aspects of both defectiveness and causation. Without such testimony, juries would be left to surmise, conjecture and speculation on these central elements of every case and cause" (Owen 2002, 347). Even in routine matters, courts have become dependent upon experts when conducting the day-to-day business of justice.

So, whenever experts are involved with a court proceeding, it is in a situation where the fact-finders are dependent upon them in an epistemic sense. Because of this, the expert often appears as an authority that judges and juries are unfit to question or challenge, and to whom judges and juries will be tempted to defer in their judgments. Yet, if this happens the trial is in effect being decided by the experts rather than the courts. This situation is only aggravated by the fact that experts often have competing opinions, and trials can easily become a "battle of the experts" which the juries, by hypothesis, do not have the capacity to adjudicate (Hand 1901, 54-5; Walton 1997, 171-6). Moreover, with the increasing dependence on expert, scientific knowledge there appears also to have been a tremendous increase in the amount of "junk science" making its way into the courts through the testimony given in the expert witness box (Huber 1991; see also Chesebro 1993; McGarity 2004). These problems speak to the need to regulate expert knowledge in the courtroom.

\section{A Brief History of the Treatment of Expert Testimony in American Law}

In order to appreciate how this regulatory problem has been treated in law, it is worthwhile to briefly examine the development of the treatment of expert knowledge by the American legal system. 


\section{Early History}

It is well known that, today, expert knowledge finds its way into the courtroom by way of the testimony of expert witnesses. The expert witness, in turn, is typically introduced in the overall context of the adversarial process as representing one or other party in the litigation. But this was not always the case. Judge Learned Hand writes:

In early times, and before trial by jury was much developed, there seem to have been two modes of using what expert knowledge there was: First, to select as jurymen such persons as were by experience especially fitted to know the class of facts which lay before them, and second, to call to the aid of the court skilled persons whose opinion it might adopt or not as it pleased. (Hand 1901, 40)

Indeed, before the adversarial system took its present form, juries functioned as investigative bodies (as opposed to deliberative ones), conducting independent inquires into the facts of a case as a means of reaching a verdict (Hand 1901, 44). It is important to keep this in mind, not only in understanding the historical development of the current system, but also to be aware of alternatives to the current system. Indeed, some features of the old system remain. While juries no longer have an investigative role and special juries are no longer convened, courts remain entitled to call upon independent, court-appointed experts.

As the jury system developed, and the idea that a fair trial involved a trial by a jury of one's peers became an entrenched principle, the method of special juries was abandoned. Further, the investigative role of juries was abandoned in the adversarial system that adopted the principle that a jury should determine a case solely on the basis of the evidence presented before it. In this context, the place of expertise in the courts changed dramatically from that of expert juries to that of expert witnesses. Expert witnesses first appeared in the early seventeenth century, and in the eighteenth century the practice was well established (Hand 1901, 45-9). Eventually, the role of the expert witness became established by statute.

\section{The Special Role of Experts}

Before considering issues surrounding admissibility and acceptance of expert testimony, it is important to understand what makes the testimony of experts legally different from other kinds of testimony and evidence. There is an important difference between the type of testimony that can be offered by an expert in contrast to a non-expert witness. Normally witnesses are quite limited in the kind of testimony they can give into evidence. While witnesses are permitted to report on those things which they directly experienced, witnessed, heard, said or did, they are generally 
denied the opportunity to give an opinion on the significance of these things, or to speculate on other related matters (such as what might be inferred from what they have experienced). ${ }^{5}$ Experts, on the other hand, are permitted much more leeway in regards to the matters on which they can offer testimony.

Perhaps most importantly, experts can offer opinions as to what inferences should be drawn from either those things they have directly experienced, or from data that they typically rely upon in their field of expertise (FRE, Rule 703). That is, within their field of expertise, experts are permitted not only to report their experience but to speculate upon (or draw inferences from) that experience, and the court will treat those speculations as testimony. Moreover, Rule 703 provides that experts are allowed to base their opinions on what might otherwise be called hearsay, in that they are allowed to take as their base data things they have not directly experienced (e.g., information contained in a lab report). In effect, this creates two kinds of evidence, often called "fact-based evidence" (which would include circumstantial evidence and direct testimony) and "opinion-based evidence" (which would include the speculative testimony of expert witnesses). Because experts are permitted to offer "opinion-based evidence," issues surrounding its classification and admissibility are especially acute.

\section{Early Determination of Expertise}

In the early days, the standard of success in the marketplace was used to qualify a person as an expert. "Expertise was implied from the expert's success in an occupation or profession which embraced that knowledge" (Faigman et al. 1994, 1804). Faigman et al. identify several problems with this approach. First, the marketplace test is too broad because "[t]he market not only selects for validity, it selects also for entertainment, desire, wishful thinking, hope, sometimes even desperation [...] The marketplace test is incapable of distinguishing astrophysics from astrology" (Faigman et al. 1994, 1805). Secondly, the marketplace test is too narrow since some fields of knowledge have little or no market value (ibid.). Finally, the marketplace test "conflates the expert and the expertise" (ibid.), and so fails to ensure the reliability of the testimony.

\footnotetext{
${ }^{5}$ Federal Rule of Evidence 701 provides certain exceptions for this prohibition, stating that "the witness testimony in the form of opinions or inferences is limited to those opinions or inferences which are (a) rationally based on the perception of the witness, and (b) helpful to a clear understanding of the witness' testimony or the determination of a fact at issue, and (c) not based on scientific, technical, or other specialized knowledge [. . .]." In effect, witnesses can be permitted to report on the inferences they made, or opinions they formed, on the basis of their experience. In general though, witnesses are not permitted to speculate upon matters beyond their own experience, or on the probative significance of the facts to which they are testifying.
} 
In view of the failings of the marketplace test, another standard of admissibility was required. From this point on, the treatment of expert testimony in the American legal system is usually described in relation to a series of landmark rulings as well as the adoption of the Federal Rules of Evidence. Each of these rules and rulings either sets or clarifies the standard of admissibility for expert testimony, and together they describe the history of the development of this standard.

\section{Frye}

The first of these landmark decisions is Frye. ${ }^{6}$ In 1923, the Court of Appeals of the District of Columbia was called upon to determine the admissibility of the results of a systolic blood pressure deception test as indicative of the truthfulness of a defendant. (The systolic blood pressure test was an early version of current polygraph "lie-detector" devices.) The test was based on "[a scientific] theory which seems to be that the truth is spontaneous [...] while the utterance of a falsehood requires a conscious effort, which is reflected in the blood Pressure" (Frye at 1014). In order to accept the significance of the test results, the court was being asked to accept the truth of this theory. In effect then, the expert testimony was offered not only to report the results of the test itself, but also in support of the truth of the theory behind the test. The problem was that the test and the theory behind it were rather novel at that time.

To resolve this problem, the court prescribed an admissibility criterion for expert testimony which has come to be known as the "general acceptance test" which the court described as follows.

Just when a scientific principle or discovery crosses the line between the experimental and demonstrable stages is difficult to define. Somewhere in this twilight zone the evidential force of the principle must be recognized, and while courts will go a long way in admitting expert testimony deduced from a well-recognized scientific principle or discovery, the thing from which the deduction is made must be sufficiently established to have gained general acceptance in the particular field to which it belongs. (Frye at 1014)

This general acceptance test became widely adopted in American courts as a criterion for admissibility of expert or scientific knowledge. As Faigman et al. describe, following Frye the test changed from the success of the expert in the marketplace, to the success the expertise in the "intellectual marketplace" (Faigman et al. 1994, 1805). According to this criterion, the results of the systolic blood pressure test were determined to be inadmissible as evidence.

${ }^{6}$ Frye v United States, 293 F. 1013, D.C. Circ., 1923. 
The apparent benefits of the general acceptance test are that it can be applied and the results determined with relative ease by a non-specialist. On the other hand, there are both theoretical and practical problems with adopting this as a stand-alone admissibility criterion for expert knowledge. A significant theoretical problem is that even a reliable, well-established methodology might, nevertheless, not be generally accepted in a field. Similarly, as Beecher-Monas writes, "much knowledge slips into general acceptance without any careful examination, especially where that knowledge has been accepted for a long time" (Beecher-Monas 1998, 60; citing Faigman et al. 1994, 1799, 1811 and n. 37; Abelson 1962, 75). A second problem is that the general acceptance test could easily produce results that contradict the "second axiom" of evidence law that "all facts having rational probative value are admissible, unless some specific rule forbids" (Wigmore 1940, 293, par. 10). Under the test, a relevant fact could be excluded merely because it is not generally accepted, or because it is based on a principle which is not generally accepted. Indeed, this was precisely the argument raised in McCormick's widely used text on evidence. There, McCormick argued that "[a]ny relevant conclusions which are supported by a qualified expert witness should be received unless there are other reasons for exclusion" (McCormick 1954, 363; as cited by Black et al. 1994, 722; see also Giannelli 1980, 1233). A third theoretical problem is what to do when there are several generally accepted theories, methodologies or principles which together yield opposing (contradictory or contrary) claims.

The possibility of competing theories leads to the practical problem of how to select between them. And this is but an instance of a larger practical problem raised by Black et al. (1994). Following Giannelli (1980, 1208-23), Black et al. argue that "a court applying Frye has to decide what must be accepted, what constitutes the relevant field of science, and what demonstrates acceptance, and making these decisions requires the very understanding of science that Frye ostensibly avoids" (Black et al. 1994, 726-7). As such, it would seem that the standard of general acceptance does not provide a sound or practical admissibility criterion for expert testimony.

\section{Federal Rules of Evidence}

In the wake of criticisms like these, the United States Congress adopted the Federal Rules of Evidence in 1975. These Rules specified a new standard of admissibility for expert testimony stated in FRE, Rule 702 as follows (see Daubert at 588; Berger 2001, 292, n. 14):

If scientific, technical, or other specialized knowledge will assist the trier of fact to understand the evidence or to determine a fact at issue, a witness qualified as expert by knowledge, skill, experience, training or education, may testify thereto in the form of an opinion or otherwise. (FRE, Rule 702) 
Not only does FRE, Rule 702 abandon the standard of general acceptance, but it explicitly seeks to include any knowledge that will be helpful to the trier of facts in a case. As such, the first general standard of admissibility is that of relevance. The second general standard is reliability, although the reliability criterion is only implicitly stated in the original rule. ${ }^{7}$ In effect, the Federal Rules of Evidence changed the admissibility criterion for expert testimony from general acceptance to relevance and reliability.

While the criteria of relevance and reliability appear to be more substantive than general acceptance, several problems occurred following their introduction in the Federal Rules of Evidence. In addition to the vague criteria of reliability originally provided, the Rule did not make any reference to the Frye decision, and so appeared not to take into account the general acceptance criterion articulated therein. This left many courts in an interpretive vacuum, and many still applied the more intuitive general acceptance criterion of Frye.

Haack (2003) characterizes the interval following the adoption of the Federal Rules of Evidence as a period in which it remained unclear whether the Federal Rules were superseded by, or complemented by the Frye Rule. On her description, this interval has been characterized by legal wrangling over expert testimony in which science has become entangled with law in a "bramble bush." The evolving set of rules, precedents and standards set by the law to handle scientific evidence has been "entangled" with controversies on fundamental issues of how expert testimony can be defined as a kind of evidence based on scientific input.

For Haack $(2004,15)$ the problem arises from the tension between the adversary system of American legal culture and the open-ended fallibilism of scientific research. Advocacy may be defined as an attempt to make a case for the truth of some designated proposition by arguing for it in order to persuade an audience to accept it. In contrast, scientific inquiry is an attempt to discover the truth of some question by seeking out all the possible evidence available, and drawing only such conclusions as the evidence warrants. As Haack $(2004,18)$ describes it, the conflict between these two procedures is a clash of cultures. From our point of view, we see the clash as a difference between two types of dialogue or investigative

\footnotetext{
7 Subsequently, in its Daubert decision (1993), the Federal Supreme Court would rule that the criterion of reliability was implicit in the notion of "scientific knowledge" mentioned in Rule 702. In part, the Court found as follows: "[ $t$ ]he subject of an expert's testimony must be 'scientific [...] knowledge.' The adjective 'scientific' implies a grounding in the methods and procedures of science. Similarly, the word 'knowledge' connotes more than subjective belief or unsupported speculation. The term 'applies to any body of known facts or to any body of ideas inferred from such facts or accepted as truths on good grounds.' [Webster's Third New International Dictionary 1252 (1986)] [. . .] In short, the requirement that an expert's testimony pertain to 'scientific knowledge' establishes a standard of evidentiary reliability" (Daubert at 589).
} 
procedures, with different standards of evidence and different burdens of proof that are applied to the same sequence of argumentation. In our terms, there is a shift from one context of investigation to another, a shift from a scientific inquiry dialogue to a persuasion dialogue of the kind that takes place in a trial.

\section{Daubert v Merrell Dow Pharmaceuticals}

For almost 20 years this interpretative vacuum and legal "bramble bush" remained, until 1993 when the Federal Supreme Court ruled in the matter of Daubert v Merrell Dow Pharmaceuticals. In the Daubert case several crucial facts at issue depended on the admissibility of scientific evidence indicating a causal relationship between the ingestion of Bendectin (a prescription drug for morning sickness) during pregnancy and subsequent birth defects in children. Previously, this evidence had been deemed inadmissible by the court because it had not been published and did not meet the general acceptance criterion.

The Supreme Court determined that the Federal Rules of Evidence superseded the Frye test, and thus affirmed the standard of relevance and reliability. In regards to the Frye standard, the Court found that "[n]othing in the text of this Rule [702] establishes 'general acceptance' as an absolute prerequisite to admissibility" (Daubert at 588). Instead, the Court affirmed that "[a]ll relevant evidence is admissible" subject to specific exclusionary conditions (FRE, Rule 402; see Daubert at 587). ${ }^{8}$ Further, in affirming the standard of reliability, the Court ruled that "under the Rules the trial judge must ensure that any and all scientific testimony or evidence admitted is not only relevant but reliable" (Daubert at 589).

This ruling was seen to ascribe a "gatekeeper" role to trial judges, placing on them a duty to examine and evaluate the soundness of the scientific theories being employed in their courts. Aware that the Rules of Evidence did not provide any explicit criteria for the determination of reliability, the Supreme Court attempted to provide some guidelines that could be used to assist in decisions about the admissibility of expert knowledge. The Court provided some general criteria that have come to be known as the "Daubert factors":

(1) Testability: "whether it [the evidence, theory or technique] can be (and has been) tested"

(2) Error Rate: "the known or potential rate of error"

(3) Peer Review: "whether the theory or technique has been subjected to peer review and publication"

\footnotetext{
8 The Rules define "relevant evidence" as evidence having "any tendency to make the existence of any fact that is of consequence to the determination of the action more probable or less probable than it would be without the evidence" (FRE, Rule 401; see Daubert at 587).
} 
(4) General Acceptance: the "explicit identification of a relevant scientific community and an express determination of a particular degree of acceptance within that community". (Daubert at 594)

In addition to these four generally cited criteria, Owen (2002, 358; following the notes to the amendment of FRE, Rule 702) cites a fifth criterion:

(5) Control Standards: whether its operation has been subjected to appropriate standards of control [italics added].

These criteria mark the first explicit statements by the Court of the criteria which could be employed in reaching admissibility decisions. Importantly, the Daubert factors were introduced by the Court not as a universal and exhaustive check-list (Daubert at 594) but as guidelines, to be applied where appropriate, perhaps with other relevant and useful criteria. Procedurally, these criteria are applied in pre-trial "Daubert hearings" held for the sole purpose of determining the admissibility of an expert's testimony in a given case. However, even following the introduction of these explicit Daubert factors, unresolved problems remained.

\section{General Electric Co. $v$ Joiner}

One of the first matters to be settled was the degree of discretion that courts had in applying these Daubert factors and making determinations regarding the admissibility of expert testimony. In 1997, the Federal Supreme Court ruled that neither Daubert nor the Federal Rules of Evidence gave an appeal court any special grounds or power to overturn a decision of admissibility made by a lower court. Instead, courts retained discretionary autonomy in making admissibility decisions, and "abuse of discretion is the proper standard of review of a district court's evidentiary rulings" (Joiner ${ }^{9}$ at 141).

Eventually, following the Kumho decision (see below) at least three dimensions of discretionary autonomy would be established regarding determinations of the admissibility of expert testimony: (i) "procedural discretion" concerning when and how to conduct reliability analysis; (ii) "substantive discretion" concerning what factors ought to be considered; and finally (iii) "decisional discretion" concerning the results of the reliability analysis (Harvard Law Review 2003, 2146). ${ }^{10}$

A second, important feature of the Joiner decision pertains to the instruction, apparent in Daubert, that admissibility decisions should consider only

\footnotetext{
${ }^{9}$ General Electric Company v Joiner, 522 U.S. 136, 1997.

${ }^{10}$ Problematically, these discretions-especially substantive and decisional discretion-have led to contradictory findings from one court to the next (Harvard Law Review 2003, 2146-9).
} 
methodological issues and not the acceptability of the results. The Court in Daubert found that "[t]he focus, of course, [on determinations or reliability] must be solely on principles and methodology, not on the conclusions that they generate" (Daubert at 595). Against this the Court in Joiner ruled that "conclusions and methodology are not entirely distinct from one another" (Joiner at 146), and hence that a trial judge could consider the acceptability of the results (or conclusions) of an expert as well as his or her methodology. This too served to increase the court's substantive discretion in admissibility decisions.

The general idea informing these rulings seems to be that the Daubert factors are guidelines whose purpose is to assist courts in making admissibility decisions, rather than epistemological "security checks" which must be rigorously applied by the courts and through which every expert's testimony must pass.

\section{Kumho Tire Co. $v$ Carmichael}

Another challenge to the Daubert decision concerned whether the Daubert factors applied only to scientific evidence, or to other kinds of evidence that might be considered expert testimony. In 1999 the United States Supreme Court found that the "language [of Rule 702] makes no relevant distinction between 'scientific' knowledge and 'technical' or 'other specialized' knowledge. It makes clear that any such knowledge might become the subject of expert testimony" (Kumho at 147).

Not only did the Court find that there were no grounds to distinguish between scientific and other technical or specialized knowledge in classifying testimony as expert, it also found that the attempt to do so would be impractical.

Finally, it would prove difficult, if not impossible, for judges to administer evidentiary rules under which a gatekeeping obligation depended upon a distinction between "scientific" knowledge and "technical" or "other specialized" knowledge. There is no clear line that divides the one from the others [...] Neither is there a convincing need to make such distinctions. Experts of all kinds tie observations to conclusions through the use of what Judge Learned Hand called "general truths derived from [...] specialized experience" [Hand 1901, 54]. (Kumho at 148)

What seems to be the determining factor here is not whether the testimony is scientific in nature, so much as whether the information it presents is "beyond the ken" (Krigis 2002, 512) of the normal juror (or judge), and outside of the general background knowledge jurors might reasonably be presumed to possess.

In determining the scope of knowledge that might qualify as expert testimony, the Court in Kumho made the important point that the testimony need not be based on a theoretical knowledge of a field and relying on "the 
application of scientific principles," but could instead be based on "skill- or experience-based observation" (Kumho at 151; citing Carmichael ${ }^{11}$ at 1435). For instance, the Kumho court considers the example of "a witness whose expertise is based purely on experience, say, a perfume tester able to distinguish among 140 odors at a sniff" (Kumho at 151).

Having clarified the scope of knowledge that might qualify as expert testimony, the Court in Kumho went on to find that the admissibility criteria applied to this testimony should reflect the different bases from which this knowledge is drawn. Because of this, the Court reiterated that "Daubert makes clear that the factors it mentions do not constitute a 'definitive checklist or test' [Daubert at 593]" for admissibility (Kumho at 150). Rather, "a trial court should consider the specific factors identified in Daubert where they are reasonable measures of the reliability of expert testimony" (Kumho at 152). In general, the Court in Kumho found that it was the responsibility of the trial judge to ensure that expert testimony was relevant and reliable, but that the criteria to be used in making this determination should be specifically matched to the testimony under consideration. Thus reliability criteria are, to a significant degree, contextdependent and situation-specific.

\section{Amendment to FRE, Rule 702}

To reflect the developments made in the courts, in 2000 several amendments were made to the Federal Rules of Evidence with the aim of clarifying the Rules and eliminating loopholes. For instance, Rule 701 was amended to eliminate the possibility of "proffering an expert in lay-witness clothing" (FRE, Rule 701, notes). This was achieved by distinguishing between expert and lay testimony as opposed to expert and lay witnesses (ibid.), and requiring that any testimony classified as expert (i.e., "based on scientific, technical, or other specialized knowledge"; ibid.) be subject to scrutiny regarding its reliability.

Further, Rule 702 was amended as follows to include a specific statement of three admissibility criteria for expert testimony.

[A qualified expert may testify] if (1) the testimony is based upon sufficient facts or data, (2) the testimony is a product of reliable principles and methods, and (3) the witness has applied the principles and methods reliably to the facts of the case. ${ }^{12}$

Following its amendment, Rule 702 clarifies the notion of reliability by specifying three individually necessary but jointly sufficient standards that constitute reliability.

11 Carmichael $v$ Samyang Tire Inc., 131 F.3d 1433, 1997.

12 This amendment was added directly to the end of the original Rule 702 (stated above), the text of which was otherwise unchanged. 
1. sufficiency of facts or data

2. reliability of principles and methods

3. reliability of application of these principles and methods to the facts of the case.

So, while there is no universal test for determining whether any given piece of testimony qualifies as expert, opinion-based evidence, it is necessary that the standards of reliability and relevance be met in each case.

As to how the standard of reliability is to be met in any given instance, the Rules of Evidence leave this largely to the discretion of individual trial judges. While affirming the Daubert factors as useful guidelines, the notes to the FRE, Rule 702 amendment also suggest the following additional criteria.

1. Whether experts are "proposing to testify about matters growing naturally and directly out of research they have conducted independent to the litigation, or whether they have developed their opinions expressly for the purposes of testifying" [Daubert at 1317].

2. Whether the expert has unjustifiably extrapolated from an accepted premise to an unfounded conclusion [with reference to Joiner at 146].

3. Whether the expert has adequately accounted for obvious alternative explanations [with reference to Claar $v$ Burlington ${ }^{13}$ ].

4. Whether the expert "is being as careful as he would be in his regular professional work outside his paid litigation consulting" [Sheehan v Daily Racing Form Inc. ${ }^{14}$ at 942].

5. Whether the field of expertise claimed by the expert is known to reach reliable results for the type of opinion the expert would give [with reference to Kumho at 1175]. (FRE, Rule 702, notes; see also Owen 2002, 361-2)

The Rules allow that no criterion is individually necessary, and further allow that other factors may also be relevant (ibid.). Indeed, since the revision of the Rules, other criteria have also been suggested. For example, the Harvard Law Review $(2003,2144)$ lists other factors that have been considered by other courts. Among these they cite:

6. "the technique's relationship to other techniques established to be reliable"

7. "the non-litigation-related uses to which the method has been put"

8. "whether he [the expert] has sufficiently connected his testimony with the facts of the case." (Ibid.)

Together, all of these factors contribute to the assessment of the reliability and relevance of testimony offered as expert knowledge and so help to determine the admissibility of the testimony.

${ }^{13}$ Claar v Burlington N.R.R., 29 F. 3d 499, 9th Cir., 1994.

14 Sheehan v Daily Racing Form, Inc., 104 F.3d 940, 7th Cir., 1997. 
Yet, as with all other evidence in a trial, the determination of admissibility is not the only stage for the assessment for expert testimony. Like other evidence presented in a court, expert testimony is effectively tested twice. First it must meet the court's criteria for admissibility as evidence. Second, its merit, weight or significance will be tested through the normal adversarial process of the trial system. At this second stage the evidence of the expert is evaluated not for its admissibility, but for its acceptability. It is here where it will be determined whether the expert testimony has met the burden of persuasion with respect to the particular facts at issue relevant to the expert testimony.

Importantly then, the Daubert factors are not criteria for the acceptability of expert testimony; rather, this is determined at trial. The Court in Daubert ruled, "[v]igorous cross-examination, presentation of contrary evidence, and careful instruction on the burden of proof are the traditional and appropriate means of attacking shaky but admissible evidence" (Daubert at 596). The adversarial process can involve many other factors pertinent to the assessment of testimony presented as expert knowledge, such as cross-examination and the evidence of other, conflicting expertise. Importantly, the opposing lawyer can re-ask all or some of the questions which were put to the expert at the Daubert hearing. This can have at least two functions, one positive and one negative. First, since the jury (if any) will not have heard of the expert's successful answers in the Daubert hearing, presenting them will increase the credibility of the expert. On the other hand, should an opposing lawyer feel that some of the expert's responses in the Daubert hearing were weak or unacceptable, then he could try to expose that to the jury.

In summary, the admissibility requirements for expert testimony are that it is relevant and reliable. Expert testimony need not be based on theoretical knowledge, but can also be based on skill or experience. In part because of this, there are a variety of factors that have been recommended in order to determine whether the testimony qualifies as expertise. None of these factors are either necessary or sufficient. Instead, they may be considered insofar as they are "reasonable measures of reliability" (Kumho at 152). Trial judges have procedural, substantive and decisional discretion in determining when and how to determine admissibility, what factors should be considered and the results of the tests.

Given this situation, the question of how these factors ought to be considered arises. What status do they have in the context of the legal procedure? What is the legal effect of posing one of these criteria to a potential expert, and what are the obligations of the potential expert in responding to them? In the remainder of the paper, we argue that argumentation theory can provide a workable and insightful model for representing and theorizing about the legal processes surrounding admissibility decisions of expert testimony. On this model, admissibility factors 
are best seen as having the status of critical questions relating to the argumentation scheme for expert opinion. Further, like critical questions, the argumentative effect of posing one of these criteria is explained in terms of shifting the burden of proof in the argumentative discussion. More broadly, then, the admissibility stage is seen as a sub-stage in a larger argumentative dialogue representing the entire trial procedure.

\section{Differences between Run-of-the-Mill Experts and Expert Opinion in Law}

One might be tempted to think that any general model for arguments involving expert opinion will not be directly applicable in a specifically legal context. After all, there are several significant differences between the way that arguments from expert opinion occur and are treated in law and in more general cases of day-to-day reasoning and argument. First, quite often our engagement with experts in everyday life occurs in a context where we are trying to get information which we do not have. For example, we consult with a doctor about a medical condition, we confer with financial advisors about investments, or we seek advice from a mechanic about servicing our motor vehicle. In these kinds of situations, our interaction with the expert might best be classified as an informationseeking dialogue. Yet, in a court proceeding, our interaction with the expert will seldom occur in the context of an information-seeking dialogue. Instead, the expert will be playing a role in trying to establish one or more of the premises being used in a persuasion dialogue (specifically, a dissent). ${ }^{15}$

Similarly, quite frequently in day-to-day argument the expert can be absent or even unidentified. Often some written source, like an encyclopedia or a scientific report quoted in the media, is cited as an authoritative source that backs up an arguer's opinion. In such a case, the authority might not even be identified, and the respondent cannot actually dialogue with the expert. By contrast, in a legal proceeding, the expert is always not only identified, but is present in person and his or her opinion can be subject to cross-examination and critical argument.

These differences might lead one to think that the general treatment of arguments from expert opinion as given in argumentation theory cannot offer much guidance to their treatment in legal contexts. We now proceed to argue that this is not the case. Indeed, we argue that the general probative function of expert testimony in a legal context can be modeled on the general scheme for argument from expert opinion given below. Expert testimony is defeasible: Not only is it subject to counter-argument (e.g., in cross-examination), and to rebuttal from other available evidence

${ }^{15}$ Although information-seeking dialogues could be nested within this larger context. 
(e.g., opposing testimony from other expert witnesses), but it is also subject to retraction should new evidence be discovered as a result of subsequent investigation. As such, even in law, expert testimony cannot conclusively establish the acceptability of a proposition. Thus the model we propose is that of the following defeasible argumentation scheme with its accompanying set of critical questions.

\section{Scheme for Argument from Expert Opinion}

Walton (2002, 49-50) gives the argument scheme as follows:

Major Premise: Source $E$ is an expert in subject domain $S$ containing proposition $A$.

Minor Premise: $E$ asserts that proposition $A$ is true (false)

Conclusion: $A$ is true (false). ${ }^{16}$

A central feature of arguments from expert opinion is that they are, in general, not conclusive but rather presumptive or plausibilistic in nature. That is, they do not lead necessarily to their conclusion, but instead provide reasonable grounds for the conclusion relative to certain epistemic circumstances. Yet, should these circumstances change (for instance, when new information is obtained) the argument could be weakened and subject to retraction. That said, plausible arguments are not without probative force. When making an assertion, an arguer (the proponent) incurs a burden of proof, and is obliged to provide reasons in support of her claim when called upon to do so. A presumptive argument meets this burden of proof, and has the argumentative effect of shifting the burden of proof to the objector (or respondent) of the argument. So, while inconclusive, such arguments provide presumptive support for a claim, subject to refutationhence the name.

Another way of looking at this feature of arguments from expert opinion is to say that they are defeasible: They are subject to defeat in light of new information. Sometimes this new information can come in the form of new data or evidence which becomes available to the participants in the argumentative dialogue. Sometimes, though, additional information can be specifically requested by one of the arguers. For instance, before accepting

16 Several variations of this scheme have appeared in the literature (for a summary see Walton 1997, chap. 3, 200; Walton 1989, 193). One such variation, presented by Walton and Reed (2003, 200) is as follows:

Major Premise: Source $E$ is an expert in subject domain $S$ containing proposition $A$.

Minor Premise: $E$ asserts that proposition $A$ (in domain $S$ ) is true (false).

Conditional Premise: If source $E$ is an expert in a subject domain $S$ containing proposition $A$, and $E$ asserts that proposition $A$ is true (false), then $A$ may plausibly be taken to be true (false). Conclusion: $A$ may plausibly be taken to be true (false). 
the testimony of an expert, we might want to know a bit more about her credentials or her credibility. To capture this feature of presumptive arguments, it is commonly noted that there is a collection of critical questions, associated with that type of argument, each of which can be posed in the form of an objection. Associated with the argument from expert opinion are the following critical questions. ${ }^{17}$

\section{Critical Questions for Argument from Expert Opinion}

1. Expertise Question: How credible is $E$ as an expert source?

1.1 What is E's name, job or official capacity, location, and employer?

1.2 What degrees, professional qualifications or certification by licensing agencies does $E$ hold?

1.3 Can testimony of peer experts in the same field be given to support E's competence?

1.4 What is $E^{\prime}$ s record of experience, or other indications of practiced skill in $S$ ?

1.5 What is E's record of peer-reviewed publications or contributions to knowledge in $S$ ?

2. Field Question: Is $E$ an expert in the field that $A$ is in?

2.1 Is the field of expertise cited in the appeal a genuine area of knowledge, or area of technical skill that supports a claim to knowledge?

2.2 If $E$ is an expert in a field closely related to the field cited in the appeal, how close is the relationship between the expertise in the two fields?

2.3 Is the issue one where expert knowledge in any field is directly relevant to deciding the issue?

2.4 Is the field of expertise cited an area where there are changes in techniques or rapid developments in new knowledge, and if so, is the expert up-to-date in these developments?

3. Opinion Question: What did $E$ assert that implies $A$ ?

3.1 Was $E$ quoted in asserting $A$ ? Was a reference to the source of the quote given, and can it be verified that $E$ actually said $A$ ?

3.2 If $E$ did not say $A$ exactly, then what $\operatorname{did} E$ assert, and how was $A$ inferred?

3.3 If the inference to $A$ was based on more than one premise, could one premise have come from $E$ and the other from a different expert? If so, is there evidence of disagreement between what the two experts (separately) asserted?

${ }_{17}$ Again, several versions of these questions have appeared in the literature (for a summary see Walton 1997, chap. 7). 
3.4 Is what $E$ asserted clear? If not, was the process of interpretation of what $E$ said by the respondent who used $E^{\prime}$ s opinion justified? Are other interpretations plausible? Could important qualifications be left out?

4. Trustworthiness Question: Is E personally reliable as a source?

4.1 Is $E$ biased?

4.2 Is $E$ honest?

4.3 Is $E$ conscientious?

5. Consistency Question: Is A consistent with what other experts assert?

5.1 Does $A$ have general acceptance in $S$ ?

5.2 If not, can $E$ explain why not, and give reasons why there is good evidence for $A$ ?

6. Backup Evidence Question: Is E's assertion based on evidence?

6.1 What is the internal evidence the expert used herself to arrive at this opinion as her conclusion?

6.2 If there is external evidence, e.g. physical evidence reported independently of the expert, can the expert deal with this adequately?

6.3 Can it be shown that the opinion given is not one that is scientifically unverifiable?

\section{Function and Probative Effect of Critical Questions}

It might be said that these critical questions codify some of the background information that is assumed by (or implicit in) the argument from expert opinion. As questions, they function to request the background information on which the success of the argument depends. As objections, they challenge the acceptability of the original argument until the additional information is found to be favorable (to the initial argument). As such, the central feature of critical questions is that, when they are posed, they act as undercutting defeaters (Pollock 1995) for the original argumentation. Until the questions are satisfactorily answered, the original argument is defective and unacceptable. Moreover, there is no burden of proof associated with posing these critical questions. The questions themselves do not have to be supported with reasons, or evidence that their answers are unfavorable to the proponent of the argument from expert opinion. Instead, it is up to the proponent to demonstrate that they can be answered. In effect then, while the argumentative result of a presumptive argument is to shift the burden of proof to an objector, the argumentative result of posing a critical question is to shift the burden of proof back to the proponent of the argument.

\section{Admissibility Criteria and Critical Questions: A Comparison}

We can now proceed to identify specific similarities between a general dialectical model for arguments involving expert opinion and related 
arguments occurring in a legal context. These similarities demonstrate both the utility and accuracy of the general model to legal argument. First, we show the similarity of the argumentative effects of the admissibility criteria and critical questions, and how the effects of each are best explained in terms of burden of proof. Then we show that the idea of critical questions can be usefully employed in characterizing the criteria of admissibility for expert testimony currently used in the American legal system by associating a variety of the admissibility criteria with critical questions mentioned above.

\section{General Features}

The first similarities to note are the general features of the admissibility criteria and critical questions. (For the purposes of this comparison, we will use the word "test" to indicate both the critical questions and the admissibility criteria discussed above.) In both cases, the employment of any individual test is at the discretion of the objector or examiner. Furthermore, the operation of burden of proof is similar with each test. First, the burden of proof to meet the admissibility criteria rests with the party wishing to introduce the expert opinion into evidence. The notes to FRE, Rule 702 read, in part, "the admissibility of all expert testimony is governed by the principles of Rule 104(a)." Under that Rule, the proponent has the burden of establishing that the pertinent admissibility requirements are met by a preponderance of the evidence. That is, as with a critical question, it is not up to the challenger to show that the expert does not meet the criteria. Further, there is no burden of proof associated with raising one of the admissibility criteria. Instead, merely raising one of these criteria shifts the burden of proof back to the proponent (the expert, or the party he or she represents, or is testifying on behalf of) in regard to the point at issue. ${ }^{18}$ Finally, the failure to meet any of these criteria acts as a defeater for the argumentation offered by the expert. The similarity of these general features gives a prima facie indication that the admissibility criteria for expert testimony employed in American law are best interpreted as functioning like critical questions in a defeasible argumentation scheme.

${ }^{18}$ It should be noted that the shifting of an overall burden of proof at trial may not arise purely as a result of this kind of challenge. Certainly, the burden of persuasion would not be affected, and nor might the burden of production, especially if there is still a quantity of evidence supporting an expert's credentials. The scientific evidence offered by an expert, and challenged by challenging her expertise, will only be a part of what Wigmore called a "mixed mass of evidence," the cumulative weight of which will actually determine whether a burden of proof has been met (cf. Wigmore 1940, 270-86, pars. 2485-9). The point we make here is only that there is no dialectical obligation attached to raising a challenge to one or more of the admissibility criteria for expert testimony. Rather, whatever obligations arise must be born by the proponent, and one of these is to respond to such challenges. 


\section{Specific Similarities}

Beyond these general similarities, there are also important correspondences between many of the admissibility factors identified by the American legal system, and the critical questions associated with the scheme for argument from expert opinion. For example, among the Daubert factors: The testability factor corresponds directly to the backup evidence question 6.3; the peer review factor corresponds specifically to expertise sub-question 1.5; and the general acceptance factor corresponds directly to the consistency sub-question 5.1 .

Similarly with the post-Daubert factors. Questions of bias and conscientiousness (trustworthiness sub-questions 4.1 and 4.3 respectively) roughly correspond to the post-Daubert factors 1 (independence of research factor) and 4 (carefulness factor) on our list. The criterion cited in the notes to FRE, Rule 702 concerning the general reliability of knowledge within the field of claimed expertise (no. 5 on our list) corresponds exactly to field subquestion 2.1. The criterion concerning alternative explanations cited in the notes to FRE, Rule 702 (no. 3 on our list) corresponds roughly to backup evidence question 6.3. And, the last criterion cited by the Harvard Law Review (no. 8 on our list) concerning the relation of the testimony to the facts of the case corresponds roughly to field question 2.3.

While we find these similarities remarkable, this is not to say that we find-nor should we expect to find-a direct, one-to-one correspondence between each admissibility criterion and some critical question. Indeed, we have already noted that some questions that might apply to arguments from expert opinion in an everyday context (e.g., expertise question 1.1 pertaining to the identity of the expert) would not typically apply to the situation in a legal proceeding (the expert would already be identified). On the other hand, there might be some opportunity to expand the list of critical questions for the general argumentation scheme. For example, the post-Daubert factors 2 and 3 (FRE, Rule 702, notes) could be specifically included by adding an unjust extrapolation question, and an alternative explanation question. Similarly, existing critical questions might suggest additional admissibility factors that could be considered.

The broader point, though, is that critical questions and admissibility factors resemble each other in terms of content and function. There are many similarities between the critical questions associated with the general argumentation scheme for argument from expert opinion and the factors that can be considered when determining the admissibility of testimony professed to be expertise. Moreover, the argumentative effects of these admissibility criteria which serve to shift the burden of proof back to the proponent exactly parallel the argumentative effects of critical questions. 


\section{Admissibility Criteria and Critical Questions: Some Conclusions}

These observations yield many important insights. What is most important is that argumentation theory shows how the criteria for managing expert opinion evidence need to be structured in a model that takes a dialogic setting of the argument into account. The central argumentation in a trial can be structured, in outline, as a critical discussion type of dialogue (Feteris 1999). The advocates on either side are trying to resolve a conflict of opinions by using argumentation. Importantly, general and welldeveloped dialogic models of argumentation already exist in argumentation theory, and promise to supply theoretical resources to aid in the analysis and evaluation of evidence in law.

Within this contextual framework the argumentation employed can be analysed according to argumentation schemes. These schemes are common patterns of plausible argument, and reflect the basic idea that the argumentation employed in a courtroom is by and large defeasible, and subject to refutation in the face of new, contradictory evidence. The use of such argumentation can be used to meet a burden of proof, and to shift a burden of proof to an opposing side without ever conclusively establishing the claim at issue. Further, the critical questions associated with each scheme provide a means for assessing a particular instance or segment of argumentation. While they may not serve to conclusively refute an argument, they do function as undercutting defeaters, and have the effect of shifting the burden of proof back to the proponent of a claim. As Wigmore describes, this shifting back and forth of the burden of proof seems to capture the general flow of argumentation in a trial (Wigmore 1940, 270-86, pars. 2485-9).

Perhaps the most interesting conclusion to be drawn from the comparison we have made in this paper concerns the way in which a proponent can respond when challenged regarding one of the admissibility factors. It is our view that these admissibility factors are similar in content and function to critical questions. Yet, according to the prevailing theory of critical questions, if asked, a critical question must be answered satisfactorily, otherwise the target argument is defeated. Critical questions associated with a given scheme need not be answered since they are raised at the discretion of the respondent. (Similarly, admissibility factors are raised at the discretion of the judge.) Yet, we observed that none of the admissibility criteria are individually necessary. Indeed, some of these criteria might not pertain to expertise of certain kinds. For instance, criteria pertaining to the theoretical soundness of a methodology might not be relevant to skill-based expertise. This suggests that a proponent of expert testimony need not directly meet each of these criteria even if they are raised by the judge. Rather, there might be several quite different ways to show that a criterion has been met. 
For instance, when faced with one of these admissibility criteria, the proponent could attempt to meet the criterion directly. Here,

(i) the proponent shows that the criterion has been satisfied (direct answer).

On the other hand, the fact that the proponent does not directly satisfy the criteria does not immediately defeat her argument, nor does it exhaust her options for response. Another option is that

(ii) the proponent shows that the criterion is not relevant (indirect answer).

This is an indirect answer which shows that, even though the proponent does not meet the criterion, this is not a failing of her argument. Here, the reason is that the criterion does not properly pertain to the expertise professed by the proponent, and as such it is not relevant. Importantly, some criteria might be universally applicable, and hence always relevant. For instance, the admissibility criteria are intended to be reasonable measures of reliability, and some might be so inseparably tied to the idea of reliability as to be universal. The idea that knowledge be in principle testable and falsifiable might be such an example (Redmayne 2000). By contrast, other criteria (such as having a theoretically-based methodology) might not be required in order to ensure reliability of knowledge in all cases. Such a criterion, if posed to an expert, need not be directly satisfied in order to demonstrate the admissibility (i.e. reliability) of her testimony.

Finally, a proponent might choose yet another response option. Again faced with the situation of not being able to directly satisfy a criterion, a proponent might seek to show that this is not a failing of her argument on other grounds. Here,

(iii) the proponent shows that the criterion is not significant (indirect answer).

In this case, a proponent might argue that her failure to meet the criterion in question should not be given much weight in view of the fact that other criteria have been met and their collective merit outweighs the importance of this criterion. (An example might be publication of results or general acceptance.) When applied to the general theory of critical questions, these observations seem to indicate that there may be a variety of means-both direct and indirect-by which a critical question can be satisfactorily answered.

Obviously our presentation of the main legal rulings and criteria to date, along with the argumentation tools that most directly bear on them, has merely scratched the surface of this important subject. All we have 
done is to point the way to the possibilities of further research concerning the many vexing problems arising out of expert testimony in law. For instance, understanding admissibility criteria as critical questions will not help judges to understand the content of the admissibility criteria themselves (Gatowski et al. 2001). Nor will it replace the need for the judges to understand the science itself. To apply the admissibility criteria properly, judges likely require a basic knowledge of some fundamental epistemological principles and basic scientific theory in each of the specialized fields (Federal Judicial Centre 2000). Perhaps effective judges even require an awareness of some of the sociological, political and economic issues that intrude upon the practice of science seen as purely objective inquiry into the truth (Caudill et al. 2003). While our approach cannot meet all of these needs, we suggest that it offers a promising avenue for future study.

(for David M. Godden) University of Windsor

Department of Philosophy

Windsor, Ontario

N9B 3P4 Canada

E-mail: goddendm@uwindsor.ca

(for Douglas Walton)

University of Winnipeg

Department of Philosophy

Winnipeg, Manitoba

R3B 2E9 Canada

E-mail: d.walton@uwinnipeg.ca

\section{References}

Abelson, Philip H. 1962. The Need for Scepticism. Science 138: 75.

Anderson, Terence, David Schum, and William Twining. 2005. Analysis of Evidence. 2nd ed. Cambridge, MA: Cambridge University Press.

Beecher-Monas, Erica. 1998. Blinded by Science: How Judges Avoid the Science in Scientific Evidence. Temple Law Review 71: 55-102.

Berger, Margaret A. 2001. Complex Litigation at the Millennium: Upsetting the Balance between Adverse Interests: The Impact of the Supreme Court's Trilogy on Expert Testimony on Toxic Tort Litigation. Law \& Contemporary Problems 64: 289-325.

Bex, Floris, Henry Prakken, Chris Reed, and Douglas Walton. 2003. Towards a Formal Account of Reasoning about Evidence, Argument Schemes and Generalizations. Artificial Intelligence \& Law 11: 125-65.

Black, Bert, Francisco J. Ayala, and Carol Saffran-Brinks. 1994. Science and the Law in the Wake of Daubert: A New Search for Scientific Knowledge. Texas Law Review 75: 715-802. 
Caudill, David S., and Lewis H. LaRue. 2003. Why Judges Applying the Daubert Trilogy Need to Know about the Social, Institutional and Rhetorical-and not just the Methodological-Aspects of Science. Boston College Law Review 45: 1-53.

Chesebro, Kenneth J. 1993. Galileo's Retort: Peter Huber's Junk Scholarship. American University Law Review 42: 1637-726.

Damaska, Mirjan R. 1997. Evidence Law Adrift. New Haven, CT: Yale University Press.

Faigman, David L., Elise Porter, and Michael J. Saks. 1994. Check Your Crystal Ball at the Door, Please: Exploring the Past, Understanding the Present, and Worrying about the Future of Scientific Evidence. Cardozo Law Review 15: 1799-835.

Federal Judicial Centre. 2000. Reference Manual on Scientific Evidence. 2nd ed. Washington, DC: Federal Judicial Centre.

Feteris, Eveline. 1999. Fundamentals of Legal Argumentation: A Survey of Theories on the Justification of Judicial Decisions. Dordrecht: Kluwer.

Gatowski, Sophia I., Shirley A. Dobbin, James T. Richardson, Gerald P. Ginsburg, Maria L. Merlino, and Veronica Dahir. 2001. Asking the Gatekeepers: A National Survey of Judges on Judging Expert Evidence in a Post-Daubert World. Law and Human Behavior 25: 433-58.

Giannelli, Paul C. 1980. The Admissibility of Novel Scientific Evidence: Frye v United States, a Half-Century Later. Columbia Law Review 80: 1197-1223.

Gordon, Thomas F. 2005. A Computational Model of Argument for Legal Reasoning Support Systems. In Argumentation in Artificial Intelligence and Law. Ed. Paul E. Dunne and Trevor Bench-Capon. Nijmegen: Wolf Legal.

Haack, Susan. 2003. Defending Science within Reason: Between Scientism and Cynicism. Amherst, NY: Prometheus Books.

Haack, Susan. 2004. Truth and Justice, Inquiry and Advocacy, Science and Law. Ratio Juris 17: 15-26.

Hand, Learned. 1901. Historical and Practical Considerations Regarding Expert Testimony. Harvard Law Review 15: 40-58.

Harvard Law Review. 2003. Note: Reliable Evaluation of Expert Testimony. Harvard Law Review 116: 2142-63.

Huber, Peter. 1991. Galileo's Revenge: Junk Science in the Courtroom. New York, NY: Basic Books.

Krigis, Paul F. 2002. The Problem of the Expert Juror. Temple Law Review 75: 493-537.

McCormick, Charles T. 1954. Handbook of the Law of Evidence. St. Paul, MN: West Group.

McGarity, Thomas O. 2004. Our Science Is Sound Science and Their Science is Junk Science: Science-based Strategies for Avoiding Accountability and Responsibility for Risk-Producing Products and Activities. Kansas Law Review 52: 897-937.

Owen, David G. 2002. A Decade of Daubert. Denver University Law Review 80: 345-73.

Pollock, John L. 1995. Cognitive Carpentry. Cambridge, MA: MIT Press.

Prakken, Henry, and Giovanni Sartor. 1996. A Dialectical Model of Assessing Conflicting Arguments in Legal Reasoning. Artificial Intelligence and Law 4: 331-68.

Prakken, Henry, and Giovanni Sartor. 2003. The Three Faces of Defeasibility in the Law. Ratio Juris 16: 495-516.

Redmayne, Mike. 2000. A Corroboration Approach to Recovered Memories. Law Quarterly Review 116: 147-55.

Redmayne, Mike. 2001. Expert Evidence and Criminal Justice. Oxford: Oxford University Press. 
Schum, David A. 1994. The Evidential Foundations of Probabilistic Reasoning. Evanston, IL: Northwestern University Press.

Walton, Douglas. 1989. Informal Logic. New York, NY: Cambridge University Press.

Walton, Douglas. 1997. Appeal to Expert Opinion. University Park, PA: Pennsylvania State University Press.

Walton, Douglas. 2002. Legal Argumentation and Evidence. University Park, PA: Pennsylvania State University Press.

Walton, Douglas. 2005. An Automated System for Argument Invention in Law Using Argumentation and Heuristic Search Procedures. Ratio Juris 18: 434-63.

Walton, Douglas, and Chris Reed. 2003. Diagramming, Argumentation Schemes and Critical Questions. In Anyone Who Has a View: Theoretical Contributions to the Study of Argumentation. Ed. Frans H. van Eemeren, J. Anthony Blair, Charles A. Willard, and A. Francisca Snoek Henkemans. Dordrecht: Kluwer.

Wigmore, John Henry. 1940. A Treatise on the Anglo-American System of Evidence in Trials at Common Law. Vol. 1. 3rd ed. Boston, MA: Little, Brown and Company. 